\title{
Persistent fetal vasculature: ocular features, management of cataract and outcomes
}

\author{
Persistência da vasculatura fetal: características oftalmológicas, manuseio da catarata e resultados cirúrgicos
}

\author{
Marcia Beatriz Tartarella ${ }^{1}$, Rodrigo Ueno Takahagl ${ }^{1}$, Ana Paula Braga², João Borges Fortes Filho ${ }^{3}$
}

\section{ABSTRACT}

Purposes: To describe ocular features, management of cataract and functional outcomes in patients with persistent fetal vasculature.

Methods: Retrospective, descriptive case series of patients with persistent fetal vasculature. Data were recorded from the Congenital Cataract Section of Federal University of São Paulo, Brazil from 2001 to 2012. All patients were evaluated for sex, age at diagnosis, systemic findings, laterality, age at surgery, and initial and final follow-up visual acuities. Follow-up and complications after cataract surgery were recorded. Ultrasound was performed in all cases and ocular eco-Doppler was performed in most.

Results: The study comprised 53 eyes from 46 patients. Age at diagnosis ranged from 5 days of life to 10 years-old (mean 22.7 months). Twenty-seven patients were male (58.7\%). Persistent fetal vasculature was bilateral in 7 patients (15.2\%). Forty-two eyes (79.2\%) had combined (anterior and posterior forms) PFV presentation, 5 eyes (9.4\%) had only anterior persistent fetal vasculature presentation and 6 eyes (11.3\%) had posterior persistent fetal vasculature presentation. Thirtyeight eyes $(71.7 \%)$ were submitted to cataract surgery. Lensectomy combined with anterior vitrectomy was performed in 18 eyes (47.4\%). Phacoaspiration with intraocular lens implantation was performed in 15 eyes (39.5\%), and without lens implantation in 5 eyes (13.2\%). Mean follow-up after surgery was 44 months. Postoperative complications were posterior synechiae (3 cases), retinal detachment (2 cases), phthisis (3 cases), posterior capsular opacification (8 cases), inflammatory pupillary membrane (5 cases), glaucoma (4 cases), intraocular lens implantation displacement (1 case) and vitreous hemorrhage (2 cases). Complications were identified in 19 (50\%) of the 38 operated eyes. Visual acuity improved after cataract surgery in $83 \%$ of the eyes.

Conclusions: Patients with persistent fetal vasculature have variable clinical presentation. There is an association of persistent fetal vasculature with congenital cataract. Severe complications are related to cataract surgery in patients with persistent fetal vasculature, but $83 \%$ of the operated eyes improved visual acuity.

Keywords: Persistent hyperplastic primary vitreous/pathology; Cataract/congenital; Ophthalmologic surgical procedures

\section{RESUMO}

Objetivos: Descrever as características oftalmológicas, o tratamento da catarata e os resultados funcionais em pacientes com o diagnóstico de persistência da vasculatura fetal.

Métodos: Estudo retrospectivo e descritivo de série de casos de pacientes com persistência da vasculatura fetal. Dados foram obtidos dos arquivos do Setor de Catarata Congênita da Universidade Federal de São Paulo, Brasil, durante o período entre 2001 a 2012. Todos os pacientes foram avaliados quanto ao sexo, idade ao diagnóstico, achados sistêmicos, lateralidade, idade à cirurgia e acuidade visual inicial e final ao seguimento. Complicações após a cirurgia da catarata foram analisadas. Ultrassom foi realizado em todos os casos e eco-Doppler foi realizado na maioria dos pacientes. Resultados: 0 estudo incluiu 53 olhos de 46 pacientes. Idade ao diagnóstico variou de 5 dias de vida até 10 anos (média 22,7 meses). Vinte e sete pacientes eram masculinos (58,7\%). A persistência da vasculatura fetal foi bilateral em 7 pacientes $(15,2 \%)$. Quarenta e dois ol hos (79,2\%) apresentaram formas combinadas (anteriore posterior) da persistência da vasculatura fetal, 5 ol hos (9,4\%) tinham somente a forma anterior da persistência da vasculatura fetal e 6 olhos $(11,3 \%)$ tinham a forma posterior de apresentação da persistência da vasculatura fetal. Trinta e oito olhos $(71,7 \%)$ foram operados de catarata. Lensectomia com vitrectomia anterior foi realizada em $18 \mathrm{ol}$ hos $(47,4 \%)$. Facoaspiração com implante de lente intraocular foi realizada em 15 olhos (39,5\%) e sem implantação de lente em 5 olhos (13,2\%). O seguimento médio após cirurgia foi de 44 meses. Complicações pós-operatórias foram: sinéquias posteriores (3 casos), descolamento da retina (2 casos), atrofia do globo ocular (3 casos), opacificação da cápsula posterior (8 casos), membrana pupilar inflamatória (5 casos), glaucoma (4 casos), deslocamento da lente implantada (1 caso) e hemorragia vítrea (2 casos). Complicações foram identificadas em 19(50\%) dos 38 olhos operados. Acuidadevisual melhorou após a cirurgia da catarata em $83 \%$ dos olhos.

Conclusões: Pacientes compersistência davasculaturafetaltemapresentações clínicas variáveis. Existe uma associação da persistência da vasculatura fetal com catarata congênita. Complicações graves são associadas com a cirurgia da catarata nesses pacientes, mas $83 \%$ dos ol hos operados melhoraram a acuidade visual nesse estudo.

Descritores: Persistência do vítreo primário hiperplásico/patologia; Catarata/congênito; Procedimentos cirúrgicos oftalmológicos

\section{INTRODUCTION}

Persistent fetal vasculature (PFV) is a congenital developmental anomaly of the eye resulting from failure of the embryological primary vitreous and hyaloid vasculature to regress. PVF typically presents unilaterally without association with systemic findings, but sometimes PFV may be associated with rare systemic syndromes as Walker-Warburg anencephaly, oculo-dento-osseous dwarfism, oculopalato-cerebral dwarfism, Patau syndrome, or others ${ }^{(1,2)}$. Bilateral cases account for less than $10 \%$ of the cases $^{(3)}$. Persistent fetal vasculature can be classified as anterior, posterior and combined forms, according to the affected intraocular structures. This heterogeneity of clinical presentation makes PFV a challenge to surgical management ${ }^{(4)}$.

Persistent fetal vasculature is related to congenital cataract ${ }^{(5,6)}$. However, surgeries for cataract in patients with PFV are more difficult to perform and are related to higher rates of postoperative complications as: retinal detachment, hyphema, intraocular hemorrhage, glaucoma, secondary opacification of the visual axis and extensive inflammatory response with pupillary block ${ }^{(7-10)}$.
Submitted for publication: November 14,2012

Accepted for publication: March 17, 2013

Study performed at Universidade Federal de São Paulo.

Physician, Department of Ophthalmology, School of Medicine, Universidade Federal de São Paulo, São Paulo (SP), Brazil.

2 Orthoptist, Department of Ophthalmology, Universidade Federal de São Paulo, São Paulo (SP), Brazil.

3 Physician, Department of Ophthalmology, School of Medicine, Universidade Federal do Rio Grande

do Sul, Porto Alegre (RS), Brazil.
Funding: No specific financial support was available for this study.

Disclosure of potential conflicts of interest: M.B.Tartarella, None; R.U.Takahagi, None; A.P.Braga, None; J.B.Fortes Filho, None.

Correspondence address: João Borges Fortes Filho. Hospital de Clínicas de Porto Alegre. Rua Ramiro Barcelos, 2350 - Porto Alegre (RS) - 90035-903 - Brazil

E-mail: jbfortes@prorop.com.br 
This study aims to describe ocular features, management of cataract and visual acuity (VA) outcomes of patients with PFV after cataract surgery.

\section{METHODS}

\section{Study DESIGN}

A retrospective, noncomparative and descriptive case series of patients with PFV were recorded from the files of Congenital Cataract Section of Federal University of São Paulo, Brazil during the period from 2001 to 2012.

\section{Patients and ophthalmological examination}

All patients were evaluated for sex, age at diagnosis, associated systemic abnormalities, laterality, biomicroscopic examination, ocular axial length (contact A-scan measurements), initial and final follow-up VA, and intraocular pressure. Age at surgery, follow-up period and complications after cataract surgery were recorded. Indirect ophthalmoscopy and A- and B-scan ultrasonography were performed in all patients in order to evaluate components of anterior and posterior forms of PVF. Ocular eco-Doppler was performed in most patients to assess vascular blood flow. Persistent fetal vasculature was classified according to the structural ocular involvement as anterior, posterior or combined form ${ }^{(11)}$.

\section{SURGICAL TECHNIQUES USED FOR CATARACT EXTRACTION}

Lensectomy by 25 gauge bimanual vitrectomy technique was performed through the pars plicata or limbal approaches. The nucleus and cortex were aspirated in the bag. Anterior vitrectomy for removal of the PFV was performed in all cases operated by this technique. Endodiathermy was used if bleeding or in patients when the eco-Doppler examination disclosed vascular blood flow inside the fibrovascular stalk.

Phacoaspiration with or without intraocular lens implantation $(\mathrm{IOL})$ was performed through limbal incision, lens aspiration and $\mathrm{IOL}$ in the bag implantation. Posterior capsulorhexis, anterior vitrectomy and fibrovascular stalk management were performed via pars plana with 25 gauge vitrectomy system. Endodiathermy of permeable fibrovascular stalk was performed when necessary.

All surgeries were performed under general anesthesia by the same author (MBT).

\section{CRiteria for SURgery indication and MAIN OUTCOMES EVALUATED}

Surgery was indicated in cases with VA of 20/150 or less in eyes with no macular involvement. Exclusion criteria included microphthalmia and eyes with no light perception.

Postoperative VA and rate of postoperative complications were obtained. Visual acuity was assessed with age-appropriated tests such as the Teller Acuity Cards, Lea-Gratings Visual Chart, Snellen Chart, or Sweep VEP (Sweep Visual Evoked Potentials). Postoperative corrected distance $V A$ results were compared, when possible, with preoperative values and classified as: no-change; improvement or deterioration.

\section{Ethics}

The authors certify that the study protocol was approved by the Ethics Committee and that the protocol for the research project is conforming to the provisions of the Declaration of Helsinki in 1995 (as revised in Edinburgh 2000). Authors declare no financial support or relationships that may pose a conflict of interest.

\section{RESULTS}

The study group comprised 53 eyes from 46 patients. Age at diagnosis ranged from 5 days of life to 10 years-old (mean 22.7 months).
Twenty-seven patients were male (58.7\%). Persistent fetal vasculature was bilateral in 7 patients (15.2\%) and unilateral in 39 patients (84.8\%). Among the bilateral cases one patient was diagnosed as Patau syndrome and one patient had juvenile rheumatoid arthritis.

In the entire group the initial VA varied from non-light perception to $20 / 50$

Forty-two eyes (79.2\%) had combined (anterior and posterior forms) PFV presentation, 5 eyes (9.4\%) had only posterior PFV presentation and 6 eyes (11.3\%) had predominantly anterior PFV presentation.

Thirty-eight eyes $(71.7 \%)$ were submitted to cataract surgery. Age at surgery ranged from one month-age to 4 years (mean 14 months). Initial VA in the operated group of patients varied from light perception (31 eyes) to 20/150. There was no indication for surgery in patients with no-light perception and severe microphthalmia. Lensectomy combined with anterior vitrectomy was performed in 18 eyes (47.4\%). Phacoaspiration with IOL implantation was performed in 15 eyes (39.5\%), and without IOL implantation in 5 eyes (13.2\%). Fifteen eyes were not submitted to cataract surgery including one patient presenting unilateral PFV with VA of 20/50 in the affected eye.

Mean follow-up after surgery was 44 months. Postoperative complications were posterior synechiae (3 cases), retinal detachment (2 cases), phthisis bulbi (3 cases), posterior capsular opacification (8 cases), inflammatory pupillary membrane (5 cases), glaucoma (4 cases), IOL displacement (1 case) and vitreous hemorrhage (2 cases). Those complications were identified in 19 (50\%) of the 38 operated eyes.

Final corrected distance VA was obtained in 36 eyes and VA improved after surgery in $83 \%$ of eyes. Three eyes (8.3\%) developed phthisis bulbi after surgery and showed no-light perception. A total of 12 eyes (33\%) had final VA under 20/200. Seventeen eyes (47\%) showed VA between 20/200 and 20/40. Three eyes (8.3\%) achieved 20/40 or better.

None of the 15 non-operated eyes improved VA and, in this group, a total of 6 eyes decreased VA during the follow up period of the study.

\section{DISCUSSION}

This study reported predominance of unilateral cases and both anterior and posterior PFV presentation. These findings are in agreement with some previous published studies ${ }^{(10,11)}$. Some authors discuss that most cases of unilateral congenital cataracts are due to different presentations of $\mathrm{PFV}^{(5,7)}$, and that minimal fetal vascular remnants were found in $100 \%$ of a case series of 31 patients operated for unilateral congenital cataract ${ }^{(5)}$.

Cataract surgery in patients with PFV presents different degrees of difficulty, and initial surgical plan may change depending on the pre and intraoperative conditions. Ocular eco-Doppler findings showing extensive blood flow from the optic nerve to the posterior face of the lens is a predictive factor of possible intraoperative hemorrhage. The surgeon must be aware of the situation and be prepared with endocoagulation instruments and techniques to deal with the situation. Intraocular hemorrhage is a common cause of bad prognosis and poor outcomes in this PFV cases.

Membranous cataract or fibrovascular plaques at pupillary site or in the retrolental space may need further surgical manipulation with the use of micro-scissors to create a clear visual axis.

Some eyes with PFV and cataract are associated with variable degrees of microphthalmia. In these cases, the visual improvement after cataract surgery may be limited. Early surgical intervention with microsurgical 25 gauge lensectomy or phacoaspiration techniques combined with anti-amblyopic therapy resulted in favorable visual outcome in many operated eyes ${ }^{(10)}$.

Nineteen eyes (50\%) presented postoperative complications in our study. Severe complications as retinal detachment and phthisis 
bulbi occurred in 5 eyes (13\%) leading to loss of vision in those eyes. All these five eyes presented microphthalmia, combined form of PFV, a large stalk with internal blood flow and posterior retinal folds. Literature report with modern closed chamber cataract surgery in PFV showed a complication rate of $27 \%{ }^{(8)}$.

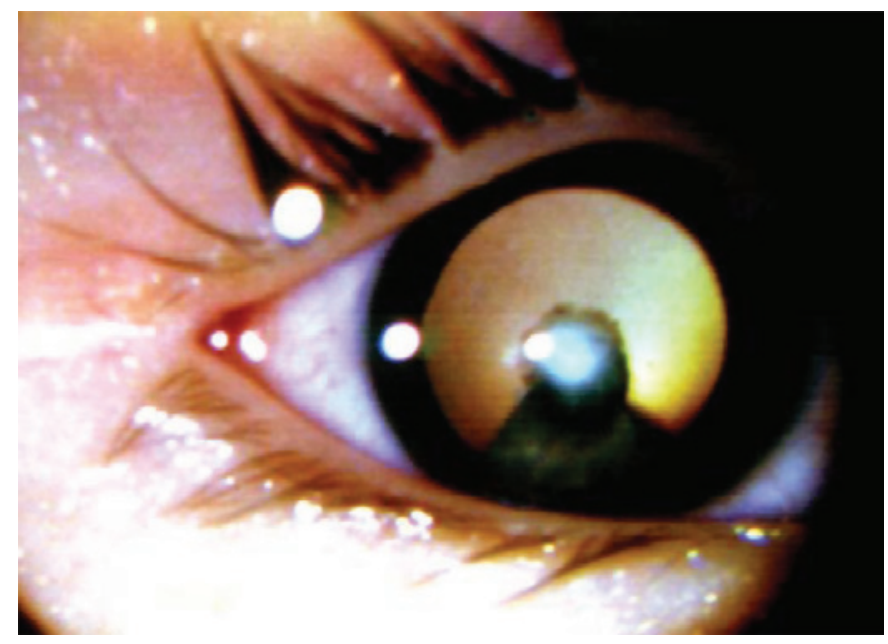

Figure 1. Patient with cataract affecting the visual axis and persistent fetal vasculature.

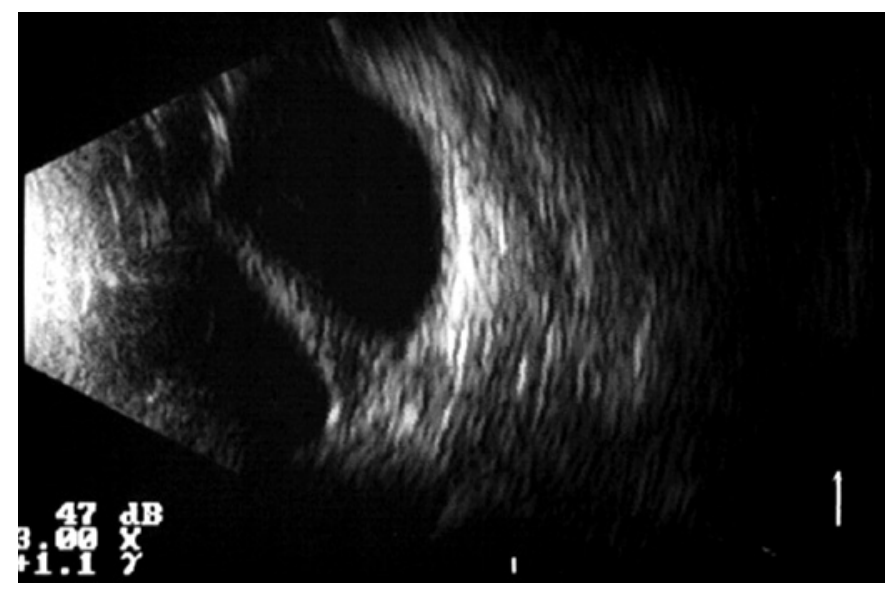

Figure 2. Ultrasound image of patient with persistent fetal vasculature in combined (anterior and posterior forms) presentation. Width of the stalk determines poor prognosis for visual acuity recovery after cataract surgery.
The prognosis after cataract surgery seems to be linked to the presentation forms of the PFV and associated preoperative ocular features. Anatomical results depend on the fibrovascular stalk width, presence of blood flow inside the stalk, type of presentation (anterior, posterior or combined form of PFV) and associated microphthalmia. Those variables are associated with the higher incidence of postoperative complications. Visual and functional results depend on age of lens opacity occurrence (congenital or latter acquired cataract formation), age at surgery and presence of major or minor macular involvement.

In our study $82 \%$ of the included eyes had initial VA of light perception and final corrected distance VA improved after surgery in $83 \%$ of the eyes despite the high rate of complications while none of the 15 non-operated eyes improved VA. Specific circumstances and clinical variables, as the occurrence of glaucoma after surgery and poor adhesion to occlusive therapy with severe amblyopia, may have also affected the final VA in those children.

New studies concerning cumulative factors that could predict prognosis for each case are necessary to help ophthalmologists to decide whether to perform surgery. Among the main pre-operatory clinical variables are: lens and vitreous opacities affecting the visual axis (Figure 1), width and occurrence of blood flow inside de stalk detected by eco-Doppler (Figures 2 and 3), retrolental vascularized plaque also detected by eco-Doppler (Figure 4), form of PFV presentation with major or minimal macular involvement (Figure 5), presence of microphthalmia and patient's age at surgery.

The surgeon and patient's parents must be aware of severe postoperative complications after cataract surgery in eyes with PFV thus causing in some cases poor VA or unfavorable outcomes. Early diagnosis, early surgery and prompt anti-amblyopic therapy after cataract surgery are important factors to be considered as functional prognostic factors.

\section{CONCLUSIONS}

Our study related that patients with persistent fetal vasculature had variable clinical presentations and there is a clear association of persistent fetal vasculature with congenital cataract. Although severe complications are related to cataract surgery in patients with persistent fetal vasculature our study disclosed that more than $80 \%$ of the operated eyes improved visual acuity despite high occurrence of intra and postoperative complications. Eco-Doppler can help in order to predict intraoperative hemorrhage and poor visual prognosis in severe forms of persistent fetal vasculature.

In spite of the limitations of this study regarding its retrospective and noncomparative design we observed visual acuity improvement in $83 \%$ of the eyes after cataract surgery and anti-amblyopic therapy in a mean postoperative follow-up of 44 months.
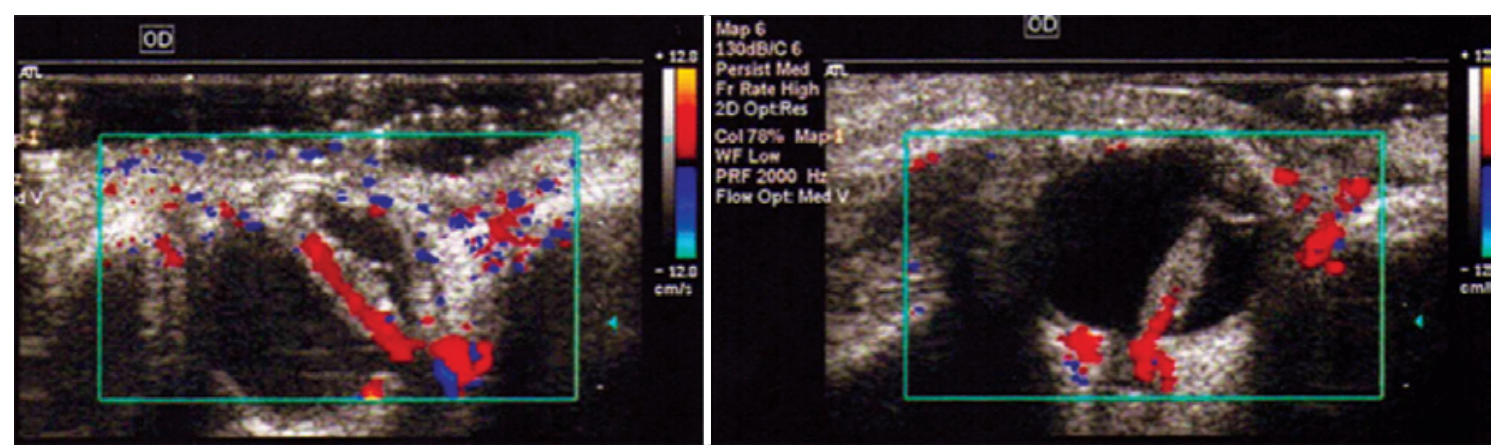

Figure 3. Eco-Doppler showing vascularized stalk from persistent fetal vasculature. Width and vascularization inside the stalk determines poor prognosis for visual acuity recovery after cataract surgery. 

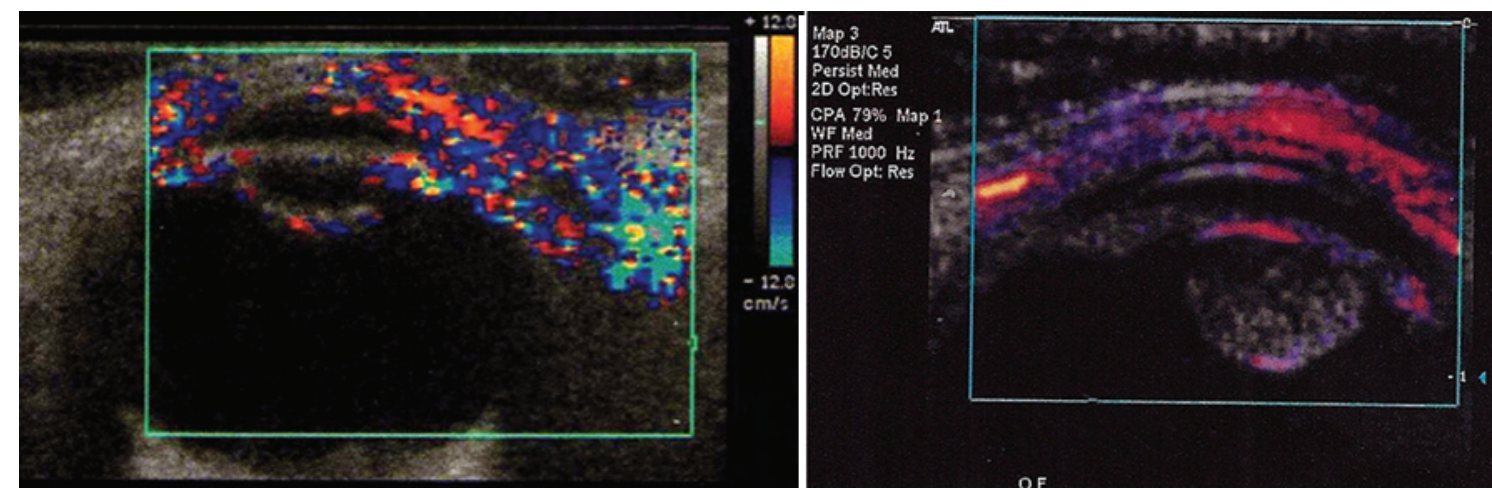

Figure 4. Eco-Doppler showing retrolental vascularized plaque from persistent fetal vasculature.
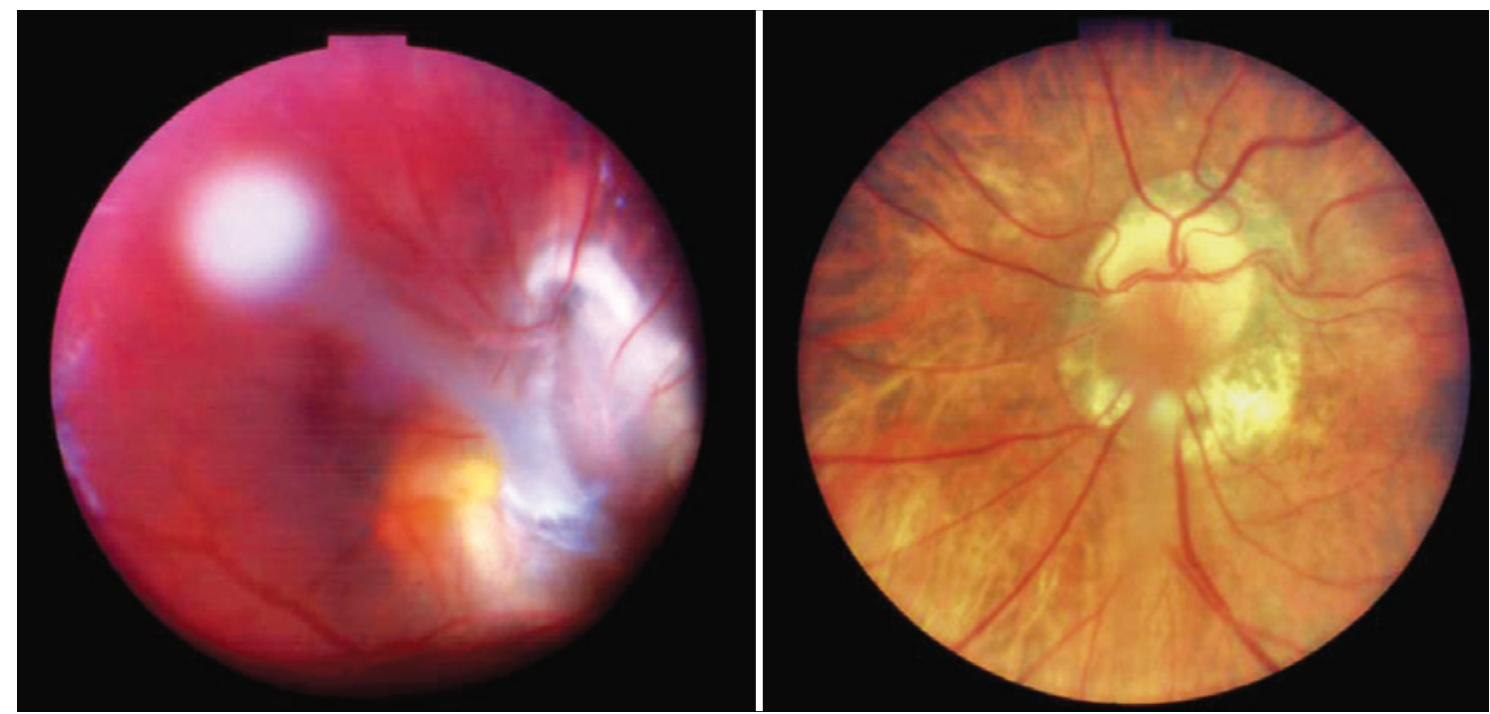

Figure 5. Persistent fetal vasculature in predominantly posterior presentation. Left: Major macular involvement suggests poor visual prognosis after cataract removal. Right: Minor macular involvement indicates better visual acuity after cataract removal.

\section{REFERENCES}

1. Alexandrakis G, Scott IU, Flynn HW Jr, Murray TG, Feuer WJ. Visual acuity outcomes with and without surgery in patients with persistent fetal vasculature. Ophthalmology. 2000;107(6):1068-72.

2. Dhir L, Quinn AG. Persistent fetal vasculature and spontaneous hyphema in a patient with Klippel-Trénaunay-Weber syndrome. J AAPOS 2010;14(2):190-2.

3. Kumar A, Jethani J, Shetty S, Vijayalakshmi P. Bilateral persistent fetal vasculature: a study of 11 cases. J AAPOS. 2010;14(4):345-8

4. Sisk RA, Berrocal AM, Feuer WJ, Murray TG. Visual and anatomic outcomes with or without surgery in persistent fetal vasculature. Ophthalmology. 2010;117(11): 2178-83.e1-2.

5. Müllner-Eidenböck A, Amon M, Moser E, Klebermass N. Persistent fetal vasculature and minimal fetal vascular remnants: a frequent cause of unilateral congenital cataracts. Ophthalmology. 2004;111(5):906-13.

6. Müllner-Eidenböck A, Amon M, Hauff W, Klebermass N, Abela C, Moser E. Surgery in unilateral congenital cataract caused by persistent fetal vasculature or minimal fetal vascular remnants: age-related findings and management challenges. J Cataract Refract Surg. 2004;30(3):611-9.

7. Paysse EA, McCreery KM, Coats DK. Surgical management of the lens and retrolenticular fibrotic membranes associated with persistent fetal vasculature. J Cataract Refract Surg. 2002;28(5):816-20. Comment in J Cataract Refract Surg. 2003;29(7): 1250

8. Vasavada AR, Vasavada SA, Bobrova N, Praveen MR, Shah SK, Vasavada VA, et al. Outcomes of pediatric cataract surgery in anterior persistent fetal vasculature. J Cataract Refract Surg. 2012;38(5):849-57.

9. Vasavada VA, Dixit NV, Ravat FA, Praveen MR, Shah SK, Vasavada V, et al. Intraoperative performance and postoperative outcomes of cataract surgery in infant eyes with microphthalmos. J Cataract Refract Surg. 2009;35(3):519-28

10. Anteby I, Cohen E, Karshai I, BenEzra D. Unilateral persistent hyperplastic primary vitreous: course and outcome. J AAPOS. 2002;6(2):92-9.

11. Dass $A B$, Trese MT. Surgical results of persistent hyperplastic primary vitreous. Ophthalmology. 1999;106(2):280-4 